\title{
Neurological Symptoms, Comorbidities, and Complications of COVID-19: A Literature Review and Meta-Analysis of Observational Studies
}

\author{
Kimia Vakilia Mobina Fathi ${ }^{a} \quad$ Mohammadreza Hajiesmaeili ${ }^{b} \quad$ Melika Salaric \\ Diksha Saluja $^{d}$ Abbas Tafakhorie Fatemeh Sayehmiria \\ Mostafa Rezaei-Tavirani ${ }^{f}$ \\ aStudent Research Committee, Faculty of Medicine, Shahid Beheshti University of Medical Sciences, Tehran, Iran; \\ ${ }^{b}$ Critical Care Quality Improvement Research Center, Loghman Hakim Hospital, Shahid Beheshti University of \\ Medical Sciences, Tehran, Iran; 'Department of Psychology, International Branch of Hormozgan Payame Noor \\ University, Kish, Iran; ${ }^{d}$ Department of Pharmacology, ISF College of Pharmacy, Moga, India; Iranian Center of \\ Neurological Science, Tehran University of Medical Sciences, Tehran, Iran; ${ }^{f}$ Proteomics Research Center, Faculty of \\ Paramedical Sciences, Shahid Beheshti University of Medical Sciences, Tehran, Iran
}

\section{Keywords}

Coronavirus disease 2019 . Neurological symptoms .

Headache - Olfactory dysfunction - Gustatory dysfunction .

Cerebrovascular disease

\begin{abstract}
Background: Recently, it has been shown that coronavirus disease 2019 (COVID-19), which has caused a pandemic since December 2019, can be accompanied by some neurological disorders. This study aimed to assess the prevalence of the most common neurological symptoms and comorbidities and systematically review the literature regarding the most prevalent neurological complications of COVID-19 infection. Methods: All relevant studies had been collected from PubMed, Scopus, Embase, and Web of Science databases. All extracted data were analyzed using Stata version 11.2. The $l^{2}$ index was applied, and a random-effects model or a fixed-effects model was used for pooled estimation to assess the heterogeneity of studies. Furthermore, Egger and Beeg's tests were used to evaluate the publication bias. $\boldsymbol{R e}$ sults: Fifty-seven studies (26 observational and 31 case reports) were included (including 6,597 COVID-19 patients). The most prevalent general symptoms were fever, cough,
\end{abstract}

and dyspnea with $84.6 \%\left(95 \% \mathrm{Cl}: 75.3-92.1 ; R^{2}=98.7 \%\right)$, 61.3\% (95\% Cl: $\left.55.3-67.0 ; R^{2}=94.6 \%\right)$, and $34.2 \%(95 \% \mathrm{Cl}$ : $\left.25.6-43.4 ; l^{2}=97.7 \%\right)$, respectively. Neurological symptoms observed among COVID-19 patients were fatigue, gustatory dysfunction, anorexia, olfactory dysfunction, headache, dizziness, and nausea with $42.9 \%\left(95 \% \mathrm{Cl}: 36.7-49.3 ; I^{2}=92.8 \%\right)$, $35.4 \%$ (95\% Cl: $\left.11.2-64.4 ; R^{2}=99.2 \%\right), 28.9 \%$ (95\% Cl: $19.9-$ $\left.38.8 ; R^{2}=96.3 \%\right), 25.3 \%\left(95 \% \mathrm{Cl}: 1.6-63.4 ; R^{2}=99.6 \%\right), 10.1 \%$ (95\% Cl: $\left.2.7-21.0 ; R^{2}=99.1 \%\right), 6.7 \%\left(95 \% \mathrm{Cl}: 3.7-10.5 ; R^{2}=\right.$ $87.5 \%)$, and $5.9 \%\left(95 \% \mathrm{Cl}: 3.1-9.5 ; P^{2}=94.5 \%\right)$. The most prevalent neurological comorbidity in COVID-19 was cerebrovascular disease with 4.3\% (95\% Cl: 2.7-6.3; $\left.\left.\right|^{2}=78.7 \%\right)$. Conclusion: The most prevalent neurological manifestations of $\mathrm{CO}$ VID-19 include fatigue, gustatory dysfunction, anorexia, olfactory dysfunction, headache, dizziness, and nausea. Cerebrovascular disorders can either act as a risk factor for poorer prognosis in COVID-19 patients or occur as a critical complication in these patients. Guillain-Barre syndrome, encephalitis, and meningitis have also been reported as complications of COVID-19.

(c) 2021 S. Karger AG, Basel

Kimia Vakili and Mobina Fathi contributed equally to the manuscript. karger@karger.com www.karger.com/ene

(C) 2021 S. Karger AG, Base

Karger"
Correspondence to:

Fatemeh Sayehmiri, fsayehmiri@yahoo.com

Mostafa Rezaei-Tavirani, tavirany@yahoo.com 


\section{Introduction}

The novel coronavirus disease 2019 (COVID-19) outbreak had infected 6,663,304 cases and caused 392,802 deaths worldwide by June 6, 2020 [1]. As the responsible virus, coronavirus 2 (SARS-CoV-2) is a highly transmissible pathogen. The most prevalent symptoms of COVID-19 are respiratory failure, fever, and dry cough [2]. Although coronaviruses do not usually cause neurological diseases, several reports indicate that the new virus can cause direct or indirect central nervous system (CNS) infections [3-5]. Moreover, several reports have shown the possible involvements of the CNS [6-8] or peripheral nervous system (PNS) [9-11], and multiple studies have revealed the presence of some neurologic symptoms [1214]. These symptoms can be categorized into several groups, including acute cerebrovascular disease, intracranial infection (such as headache, epilepsy, and consciousness impairment), PNS involvement (such as olfactory and gustatory impairment), and neuromuscular symptoms (fatigue, myalgia, muscle cramp, or increased muscle enzyme levels). Some patients may also experience sensory abnormalities, sphincter impairment, and neuralgia [15].

The structure of the viral capsid of SARS-CoV-2 involves a receptor-binding domain, which specifically recognizes the human angiotensin-converting enzyme-2 receptor [16]. ACE2, as an entrance key for SARS-COV-2, has an approximately ubiquitous expression in different human organs, including lung parenchyma, airway epithelia, nasal mucosa, gastrointestinal tract, urinary tract, reproductive organs, lymphoid tissues, vascular endothelia, and brain [17]. Under normal conditions, the ACE2 expression level in the brain is low; therefore, ACE2 alone does not seem enough to make brain cells susceptible to infection [18].

In a study conducted by Li et al. [19], potential neuroinvasion routes of SARS-CoV-2 were introduced based on data of previous respiratory viruses, with a neuroinvasive propensity and neurological symptoms of COVID-19. Two major anatomical infection routes are discovered through which SARS-CoV-2 can enter the CNS, a neural pathway through the PNS and a fluid body pathway through blood, lymph, and CSF.

1. Peripheral nerves route: contagion via droplets is almost the main transmission route of SARS-CoV-2 (close contact can also be considered an essential route of infection); therefore, the mechanism of olfactory loss and gustatory impairment may be clarified by investigating potential intranasal and oral routes of
SARS-CoV-2 to enter the CNS. In this pathway, the virus enters a nerve terminal and replicates, and then finds its route back to the CNS retrogradely [19]. Besides, SARS-CoV-2 can adhere to the nasal mucosa and directly disturb olfactory sensory neurons and olfactory epithelium by pro-inflammatory cytokines [20].

2. Hematogenous route: in a hematogenous invasion, the viruses disturb the endothelial cells in the blood-brain barrier or the blood-cerebrospinal fluid barrier and then find their way toward the CNS. In a transgenic mouse model expressing human ACE2 infected by SARS-CoV, the olfactory nerve was the main neuroinvasion route for the virus; however, some infected sites were observed in their brain indirectly connected with the olfactory bulb. Consequently, non-neuronal routes of viral infection, such as the hematogenous route, were suggested [21].

3. Lymphatic drainage of the cerebrospinal fluid route: Pathological conditions, such as viral infections, can destroy the lymphatic drainage system of the brain [22], leading to brain edema and alterations in brain structure and function, and ultimately leading to viral overflow into the perivascular space and CSF. This phenomenon may result in CNS symptoms in critical COVID-19 patients [23].

Another relationship between neurologic diseases and COVID-19 is about neurologic diseases that can coexist with COVID-19 as an underlying condition. Initial reports have revealed that cerebrovascular disease might play a substantial role in infected patients. They proposed that comorbid cerebrovascular disease, as a clinical significance, can lead to a worse prognosis in COVID-19 patients [24]. The present study aimed to investigate the relationship between COVID-19 infection and neurologic diseases by reviewing the most recent articles conducted on neurologic manifestations in COVID-19 infection, neurologic comorbidities in COVID-19 patients, and neuroinvasion mechanisms of SARS-CoV-2. The related data are analyzed to get a more quantitative perspective on these topics.

\section{Methods}

Study Selection

A Web search was conducted in PubMed, Scopus, Embase, and Web of Science databases to find eligible studies (cross-sectional, case-control, and case report) published until 17 April 2020. Two of the authors conducted the search process independently to promote accuracy. Neurological symptoms, neurologic complications, and CNS-related comorbidities in COVID-19 patients were explored using search queries, including ([Neuro-] OR [brain]) AND (COVID-19), (Neurological symptoms) 


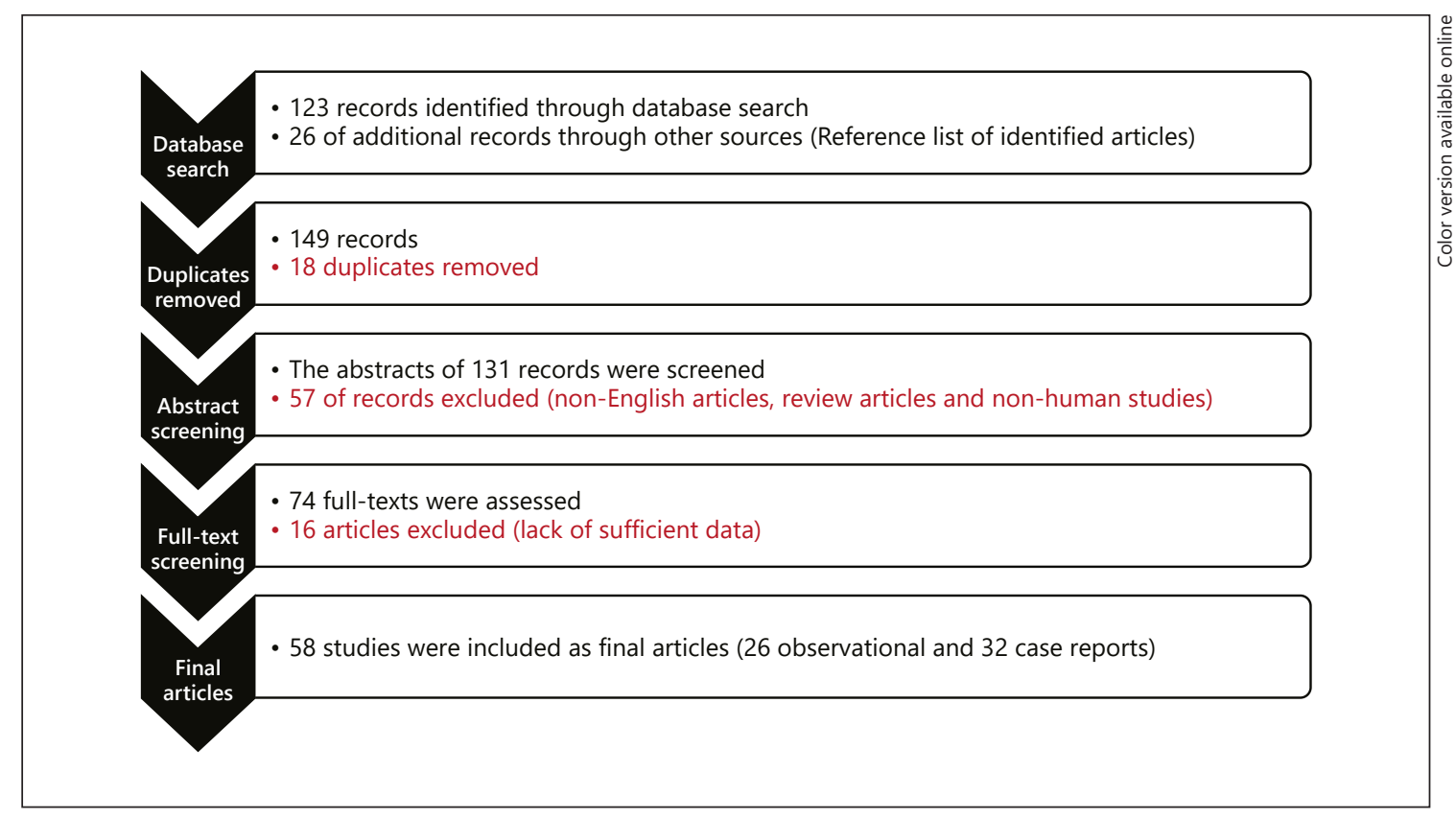

Fig. 1. Study flow diagram.

AND (COVID-19), and (Neurological complications) AND (COVID-19). At first, eligible studies were selected based on article titles. Subsequently, the reference lists of all related reviews (narrative and systematic) were searched to find more related articles.

\section{Inclusion and Exclusion Criteria}

All relevant data about neurological symptoms, neurologic complications, and CNS-related comorbidities in COVID-19 were screened to include in the final analysis. Other exclusion criteria were non-human studies, systematic review and meta-analysis studies, non-English publications, and duplicate publications.

\section{Data Extraction}

All data, including general information about the study and research team (the name of the first author, date of publication, location of publication, sample size), demographic data about the subjects (age and gender), the prevalence of general symptoms (fever, cough, and dyspnea), neurological symptoms (headache, nausea, dizziness, fatigue, Olfactory dysfunction, gustatory dysfunction, and anorexia), neurological complications (seizure, status epilepticus, Guillain-Barre syndrome [GBS], meningitis, and encephalitis), and CNS-related comorbidities (cerebrovascular disease and other nervous system diseases), were extracted from all included studies.

\section{Statistical Analysis}

The effect size was the prevalence of neurological symptoms and complications and CNS-related comorbidities; therefore, the variance was estimated using the binomial distribution. Furthermore, the average weight value was assigned to each study to combine the prevalence of various studies. The heterogeneity was as- sessed utilizing $Q$ statistics and $I^{2}$ index ( $\alpha$ significance level was $>10 \%$ ). For heterogeneous studies, the random-effects model was applied when $p$ was near 0 or meta prop command in STATA was used for the stability of variance and after the calculation of Freeman-Tukey Double Arcsine Transformation pool estimation for this proportion [25]. STATA version 11.2 was used for data analysis. Ethical approval was obtained from the Ethics Committee of Shahid Beheshti University of Medical Sciences (Ethics code: IR. SBMU.RETECH.REC.1399.082).

\section{Publication Bias}

Publication bias was graphically detected by the Funnel plot. This funnel plot is a scatter plot with 2 variates $(x, y)$, evaluating the study effect size estimates against its sample size. A linear regression analysis, including both intercept and slope parameters, was conducted for publication bias. It was calculated based on the following equation:

$$
\mathrm{y}_{i}=\alpha+\beta_{x i}+\varepsilon_{i}
$$

$i=1, \ldots, r$ ( $r=$ the number of studies $), y_{i}=$ standardized estimate, $x_{i}=$ precision of studies, and $\varepsilon_{i}=$ error terms.

\section{Quality Assessment}

The Newcastle-Ottawa Scale was employed to evaluate the quality of each included study [26] utilizing 8 assessment items, including selection, comparability, and outcome, based on the Ottawa checklist for cross-sectional studies. Based on the NewcastleOttawa Scale score standards, studies can be divided into 3 groups, including high quality (scores $\geq 7$ ), moderate quality (scores of 5-6), and low quality (scores of 0-4) the table is accessible in Appendix; see www.karger.com/doi/10.1159/000516258 for all online suppl. material). 


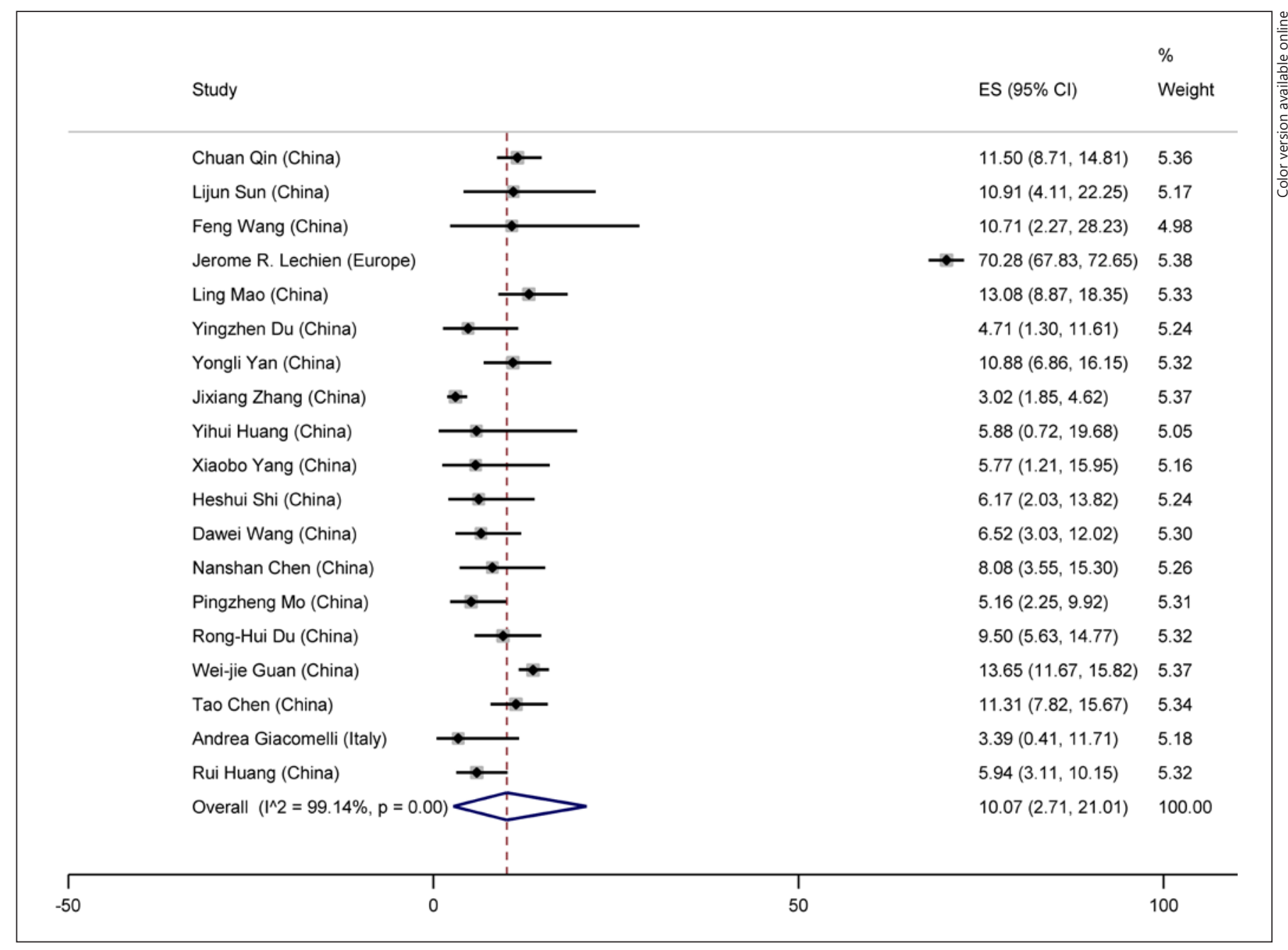

Fig. 2. Forest plot of the prevalence of headache in COVID-19 patients. Each square shows effect estimate of individual studies with their $95 \%$ CI. Size of squares is proportional to the weight of each study in the meta-analysis. In this plot, studies are shown in the order of publication date and first author's names (based on a randomeffects model). COVID-19, coronavirus disease 2019.

\section{Results}

\section{Study Selection}

This study has been conducted based on the PRISMA checklist [27]. One hundred twenty-three studies were identified after the initial database exploration. Moreover, 26 more studies were obtained from other sources (mostly by investigating a reference list of identified studies). From these 149 studies, 18 studies were duplicated and were excluded. In the next step, 57 other articles were excluded after the abstract screening. Subsequently, the full-texts of 74 remaining articles were reviewed, in which 16 articles were excluded due to the lack of appropriate data. Finally, 58 articles published from February 2020 until April 2020, including 26 observational studies and 32 case reports, were included for final analysis (Fig. 1; Table 1).

\section{Demographic Characteristics of Subjects}

Pooled together, 6,597 COVID-19 confirmed patients were included in the present study. The mean age of patients were 54.2 (95\% CI: 48.4-58.0; $\left.I^{2}=99.7 \%\right)$. Furthermore, $55 \%$ (95\% CI: $\left.50-60 ; I^{2}=100.0 \%\right)$ of the patients were male.

\section{General Symptoms}

The most prevalent general symptoms observed among COVID-19 patients were fever $(4,093 / 5,991)$, 
Table 1. Baseline characteristics of included studies

\begin{tabular}{|c|c|c|c|c|c|c|c|c|c|c|c|c|c|c|c|c|c|c|}
\hline \multirow[t]{2}{*}{ Study [ref.] } & \multirow[t]{2}{*}{ Place } & \multicolumn{3}{|c|}{ Patients, $n$} & \multirow{2}{*}{$\begin{array}{l}\text { Mean age } \\
\text { (SD) }\end{array}$} & \multicolumn{3}{|c|}{ General symptoms, \% } & \multicolumn{7}{|c|}{ Neurological symptoms, \% } & \multicolumn{3}{|c|}{ Comorbidities, \% } \\
\hline & & all & male & female & & fever & cough & dyspnea & fatigue & $\begin{array}{l}\text { gustatory } \\
\text { dys- } \\
\text { function }\end{array}$ & anorexia & $\begin{array}{l}\text { olfactory } \\
\text { dys- } \\
\text { function }\end{array}$ & haedache & dizziness & nausea & all & $\begin{array}{l}\text { nervous } \\
\text { system } \\
\text { diseases }\end{array}$ & $\begin{array}{l}\text { cerebro- } \\
\text { vascular } \\
\text { disease }\end{array}$ \\
\hline Huang et al. [1] & China & 34 & 14 & 20 & $56.24(17.14)$ & 94.1 & 50 & 14.7 & 64.7 & & & & 5.9 & & & & & \\
\hline Yang et al. [2] & China & 52 & 35 & 17 & $59.7(13.30)$ & 98 & 77 & 63.5 & 11.5 & & & & 6 & & 4 & & & \\
\hline Yang et al. [3] & China & 92 & 49 & 43 & $69.8(14.50)$ & & & & & & & & & & & 70.7 & & 10.9 \\
\hline Wu et al. [4] & China & 201 & 128 & 73 & & 93.5 & 81.1 & 39.8 & 32.3 & & & & & & & & 3.5 & \\
\hline Mo et al. [5] & China & 155 & 86 & 69 & & 81.3 & 62.6 & 2.4 & 73.2 & & 31.7 & & 9.8 & 2.4 & 3.7 & & & 4.5 \\
\hline Mao et al. [6] & China & 214 & 87 & 127 & $52.7(15.50)$ & 61.7 & 50 & & & 5.6 & 31.8 & 5.1 & 13.1 & 16.8 & & 38.8 & & \\
\hline Cao et al. [7] & China & 199 & 120 & 179 & & 91.5 & & & & & & & & & & & & 6.5 \\
\hline Shi et al. [8] & China & 81 & 42 & 39 & $49.5(11)$ & 73 & 59 & 42 & & & 1 & & 6 & 2 & 5 & 26 & & 7 \\
\hline Wang et al. [9] & China & 18 & 10 & 8 & & 94.4 & 55.6 & 22.2 & & & & & 5.6 & & 5.6 & & & \\
\hline Liu et al. [10] & China & 109 & 59 & 50 & & 82.6 & 61.5 & & 56.9 & & & & & & & & & 5.5 \\
\hline Du et al. [11] & China & 179 & 97 & 82 & $57.6(13.70)$ & 98.9 & 81.6 & 49.7 & 39.7 & & & & 9.5 & & & & & \\
\hline Du et al. [12] & China & 85 & 62 & 23 & $65.8(14.20)$ & 91.8 & 22.4 & 70.6 & 58.8 & & 56.5 & & 4.7 & & 4.7 & 68.2 & & 8.2 \\
\hline Guan et al. [13] & China & 1,099 & 637 & 459 & & 43.8 & 67.8 & 18.7 & 38.1 & & & & 13.6 & & 5 & 23.7 & & 1.4 \\
\hline Wang et al. [14] & China & 138 & 75 & 63 & & 98.6 & 59.4 & 31.2 & 69.6 & & 39.9 & & 6.5 & 9.4 & 3.6 & 46.4 & & 5.1 \\
\hline Giacomelli et al. [15] & Italy & 59 & 40 & 19 & & 72.8 & 37.3 & 25.4 & & 10.2 & & 5.1 & 3.4 & & & & & \\
\hline Chen et al. [16] & China & 99 & 67 & 32 & $55.5(13.10)$ & 83 & 82 & 31 & & & & & 8 & & 1 & & 1 & \\
\hline Lechien et al. [17] & Europe & 417 & 154 & 263 & $36.9(11.40)$ & 45 & 79 & & 58 & 88.8 & 52 & 85.6 & 45 & & 21 & & & \\
\hline Yan et al. [18] & China & 193 & 114 & 79 & & 89.6 & 69.9 & 59.6 & 52.3 & & 35.2 & & 10.9 & & 7.3 & 48.7 & & 4.1 \\
\hline Qin et al. [19] & China & 452 & 235 & 217 & & 92.6 & 33.3 & 50.8 & 46.4 & & 21 & & 11.4 & 8.1 & 9.2 & 44 & & 2.4 \\
\hline Sun et al. [20] & China & 55 & 31 & 24 & & 81.8 & 47.3 & 5.5 & 25.5 & & 12.7 & & 10.9 & 10.9 & & 32.7 & & \\
\hline Beltrán-Corbellini et al. [21] & Spain & 79 & 48 & 31 & $61.6(17.40)$ & & & & & 35.44 & & 31.65 & & & & & & \\
\hline Wang et al. [22] & China & 28 & 21 & 7 & $68.6(9.00)$ & 92.9 & 82.1 & 57.1 & 64.3 & & 57.1 & & 10.7 & & 21.4 & 60.7 & & 14.3 \\
\hline Chen et al. [23] & China & 274 & 171 & 103 & & 91 & 68 & 44 & 5 & & 24 & & 11 & 8 & 9 & 49 & & 1 \\
\hline Lechien et al. [24] & Europe & 1,420 & 458 & 962 & 39.17 (12.09) & 45.4 & 63.2 & 49.1 & & 54.2 & 45.7 & 84.37 & 70.3 & & 19.2 & & 0.9 & \\
\hline Huang et al. [25] & China & 202 & 116 & 86 & & 77.2 & 59.4 & 9.4 & 21.8 & & & & 5.9 & & 2 & 27.2 & & 1.5 \\
\hline Zhang et al. [26] & China & 663 & 321 & 342 & 55.6 & 79.5 & 61.8 & 24.3 & 31.4 & & & & 3 & 3.5 & 4.7 & & & \\
\hline
\end{tabular}

${ }^{1}$ Huang Y, et al. Clinical characteristics of laboratory confirmed positive cases of SARS-CoV-2 infection in Wuhan, China: A retrospective single center analysis. Travel medicine and infectious disease. 2020. ${ }^{2}$ Yang X, et al. Clinical course and outcomes of critically ill patients with SARS-CoV-2 pneumonia in Wuhan, China: a single-centered, retrospective, observational study. The Lancet Respiratory Medicine. $2020 .{ }^{3}$ Yang F, et al. Analysis of 92 deceased patients with COVID-19. Journal of medical virology. 2020. ${ }^{4} \mathrm{Wu}$ C, et al. Risk factors associated with acute respiratory distress syndrome and death in patients with coronavirus disease 2019 pneumonia in Wuhan, China. JAMA internal medicine. 2020. ${ }^{5} \mathrm{Mo}$ P, et al. Clinical characteristics of refractory COVID-19 pneumonia in Wuhan, China. Clinical Infectious Diseases. 2020. ${ }^{6}$ Mao L, et al. Neurologic manifestations of hospitalized patients with coronavirus disease 2019 in Wuhan China JAMA neurology $2020 .{ }^{7} \mathrm{Cao}$ B et al. A trial oflopinavir-ritonavir in adults hospitalized with severe Covid-19. New England Journal of Medicine $2020 .{ }^{8}$ Shi $\mathrm{H}$, et al. Radiological findings from 81 patients with COVID-19 pneumin in Wuh Chin Respir study. American journal of respiratory and critical care medicine. 2020;201(11):1372-1379. ${ }^{13} \mathrm{Guan}$ W-j, et al. Clinical characteristics of coronavirus disease 2019 in China. New England journal of medicine. 2020;382(18):1708-1720. ${ }^{14}$ Wang D, et al. Clinical characteristics of 138 hospitalized patients with 2019 novel coronavirus-infected pneumonia in Wuhan, China. JAMA. 2020;323(11):1061-1069. ${ }^{15}$ Giacomelli A, et al. Self-reported olfactory and taste disorders in patients with severe acute respiratory coronavirus 2 infection: a cross-sectional study. Clinical Infectious Diseases. $2020 .{ }^{16} \mathrm{Chen} \mathrm{N}$, et al. Epidemiological and clinical characteristics of 99 cases of 2019 novel coronaviru pneumonia in Wuhan, China: a descriptive study. The Lancet. 2020;395(10223):507-513. ${ }^{17}$ Lechien JR, et al. Olfactory and gustatory dysfunctions as a clinical presentation of mild-to-moderate forms of the coronavirus disease (COVID-19): a multicenter European study. European Archives of Oto-Rhino-Laryngology. 2020;1-11. ${ }^{18}$ Yan Y, et al. Clinical characteristics and outcomes of patients with severe covid-19 with diabetes. BMJ Open Diabetes Research and Care. 2020;8(1):e001343. ${ }^{19}$ Qin C, et al. Dysregulation of immune response in patients with COVID-19 in Wuhan, China. Clinical Infectious Diseases. 2020 ${ }^{20}$ Sun L, et al. Clinical Features of Patients with Coronavirus Disease 2019 (COVID-19) from a Designated Hospital in Beijing, China. Journal of Medical Virology. 2020. ${ }^{21}$ Beltrán-Corbellini Á, et al. Acute-onset smell and taste disorders in the context of COVID-19: a pilot multicentre polymerase chain rection T, et Clinicl T. et Clich he moderate coronavirus diease 2019. Journal of internal medicine. 2020. ${ }^{25} \mathrm{Huang}$ R, et al Clinical findings of patients with coronavirus disease 2019 in Jiangsu province, China: A retrospective, multicenter study. PLOS Neglected Tropical Diseases. 2020;14(5):e0008280. ${ }^{26}$ Zhang J, et al. Risk factors for disease severity, unimprovement, and mortality of COVID-19 patients in Wuhan, China. Clinical Microbiology and Infection. 2020. 


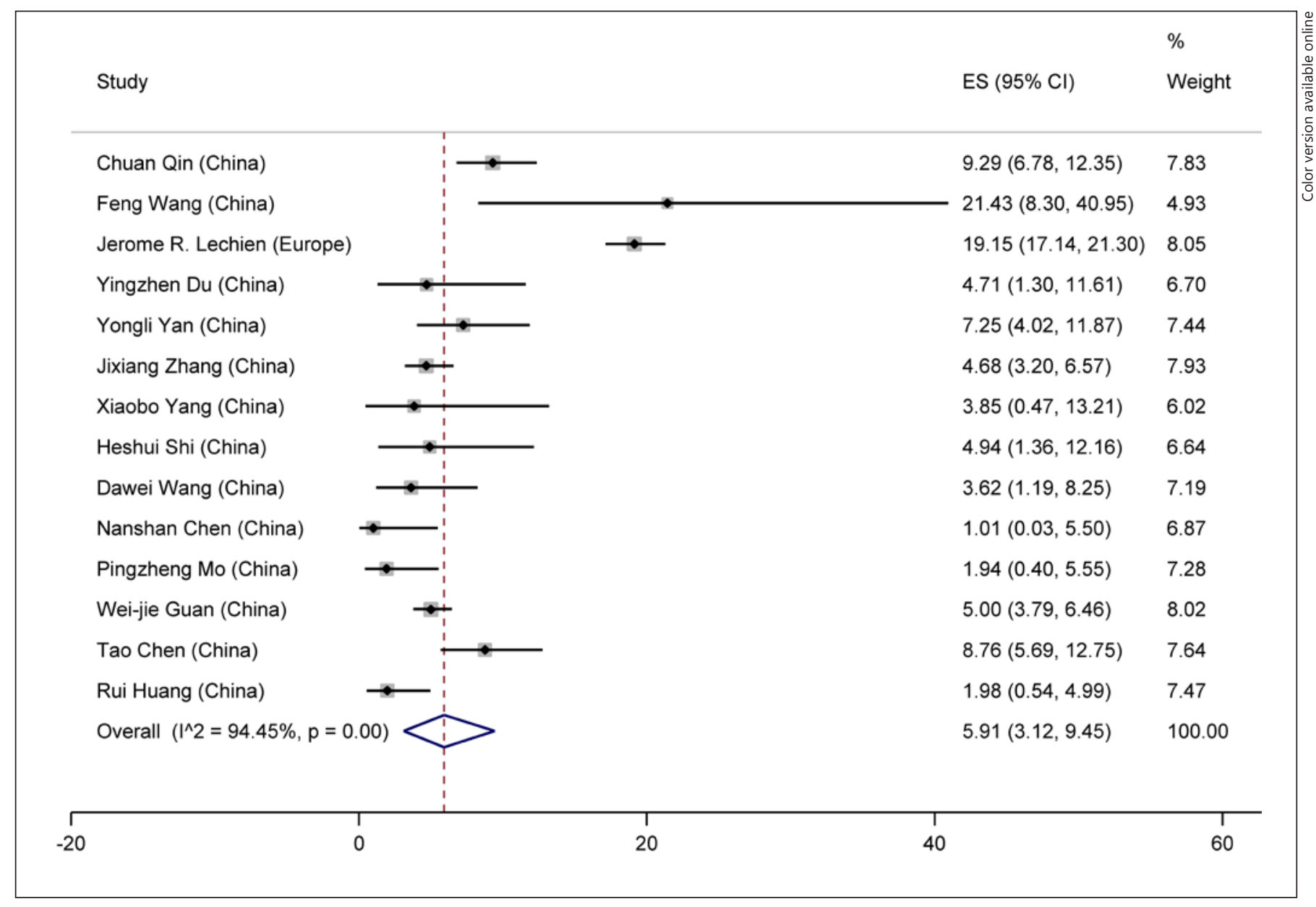

Fig. 3. Forest plot of the prevalence of nausea in COVID-19 patients. Each square shows effect estimate of individual studies with their $95 \%$ CI. Size of squares is proportional to the weight of each study in the meta-analysis. In this plot, studies are shown in the order of publication date and first author's names (based on a random-effects model). COVID-19, coronavirus disease 2019.

cough $(3,582 / 5,792)$, and dyspnea $(1,960 / 5,469)$ with 84.6\% (95\% CI: 75.3-92.1; $I^{2}=98.7 \%$ ), 61.3\% (95\% CI: 55.3-67.0; $I^{2}=94.6 \%$ ), and $34.2 \%$ (95\% CI: 25.6-43.4; $\left.I^{2}=97.7 \%\right)$, respectively.

\section{Neurological Symptoms}

Neurological symptoms in COVID-19 patients were fatigue $(1,583 / 3,919)$, gustatorydysfunction $(1,158 / 2,189)$, anorexia $(1,100 / 3,095)$, olfactory dysfunction $(1,594 / 2,189)$, headache $(1,379 / 5,482)$, dizziness $(140 / 2,032)$, and nausea $(467 / 4,941)$ with $42.9 \%$ (95\% CI: $36.7-49.3 ; I^{2}=92.8 \%$ ), 35.4\% (95\% CI: $11.2-64.4 ; I^{2}=$ 99.2\%), 28.9\% (95\% CI: $19.9-38.8 ; I^{2}=96.3 \%$ ), $25.3 \%$ (95\% CI: $\left.1.6-63.4 ; I^{2}=99.6 \%\right), 10.1 \%$ (95\% CI: $2.7-21.0$; $\left.I^{2}=99.1 \%\right), 6.7 \%\left(95 \%\right.$ CI: $\left.3.7-10.5 ; I^{2}=87.5 \%\right)$, and $5.9 \%$
(95\% CI: 3.1-9.5; $I^{2}=94.5 \%$ ), respectively (Fig. 2-8; Table 2).

\section{Neurological Complications}

Neurological complications of COVID-19 have been mostly reported in the case report articles; therefore, the data were extracted from these articles and pooled together, as presented in Table 3.

\section{CNS-Related Comorbidities}

A great number of COVID-19 patients had comorbid conditions $(1,070 / 2,913) 43.9 \%$ (95\% CI: 35.1-53.1; $I^{2}=$ $95.2 \%)$. The prevalence of underlying nervous system disease among these patients was $(21 / 1,720) 1.5 \%$ (95\% CI: $\left.0.3-3.6 ; I^{2}=69.6 \%\right)$, while the most prevalent neurologi- 


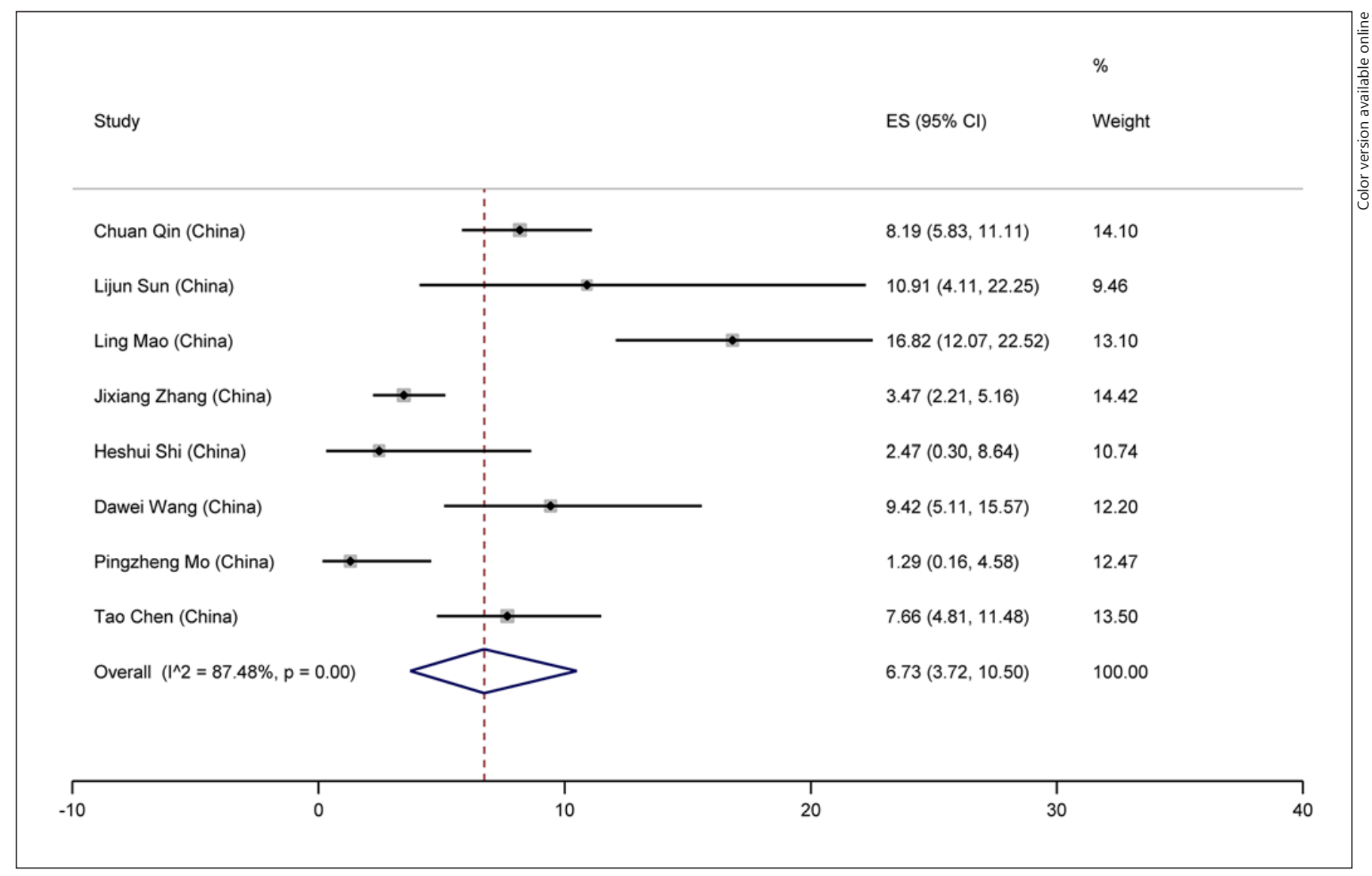

Fig. 4. Forest Plot of the prevalence of dizziness in COVID-19 patients. Each square shows effect estimate of individual studies with their $95 \%$ CI. Size of squares is proportional to the weight of each study in the meta-analysis. In this plot, studies are shown in the order of publication date and first author's names (based on a randomeffects model). COVID-19, coronavirus disease 2019.

cal comorbidity was cerebrovascular disease $(101 / 3,107)$ 4.3\% (95\% CI: $2.7-6.3 ; I^{2}=78.7 \%$ ) (Fig. 9).

\section{Publication Bias}

Figure 10 demonstrates the Begg's funnel plot for related studies. The plot interpretation revealed a sign of publication bias $(p=0.03)$, indicating that both negative and positive results have not been published (Fig. 10).

\section{Discussion}

COVID-19 has rapidly spread throughout the world [28]. A wide range of symptoms and signs of COVID-19, including fever, cough, dyspnea, fatigue, diarrhea, and vomiting, have been reported in previous studies. However, some COVID-19 patients are asymptomatic [29].
The incubation period of this disease is approximately between 2 and 11 days, and its mortality rate is about $2-4 \%[30,31]$. In this study, the calculated prevalence of the most common general symptoms of this disease, including fever, cough, and dyspnea, was $84.6 \%$ (95\% CI: $75.3-92.1 ; I^{2}=98.7 \%$ ), 61.3\% (95\% CI: 55.3-67.0; $I^{2}=$ $94.6 \%$ ), and $34.2 \%$ (95\% CI: $25.6-43.4 ; I^{2}=97.7 \%$ ), respectively, which is in good agreement with previous measures [32].

This disease can cause acute respiratory distress syndrome in severe cases, which can be a lethal condition. Other aspects of this disease, such as cardiovascular manifestations and renal complications, are being identified every day. Although most articles imply that COVID-19 mainly affects the respiratory and cardiovascular system, growing pieces of evidence are showing that neurological symptoms (such as fatigue, headache, dizziness, 


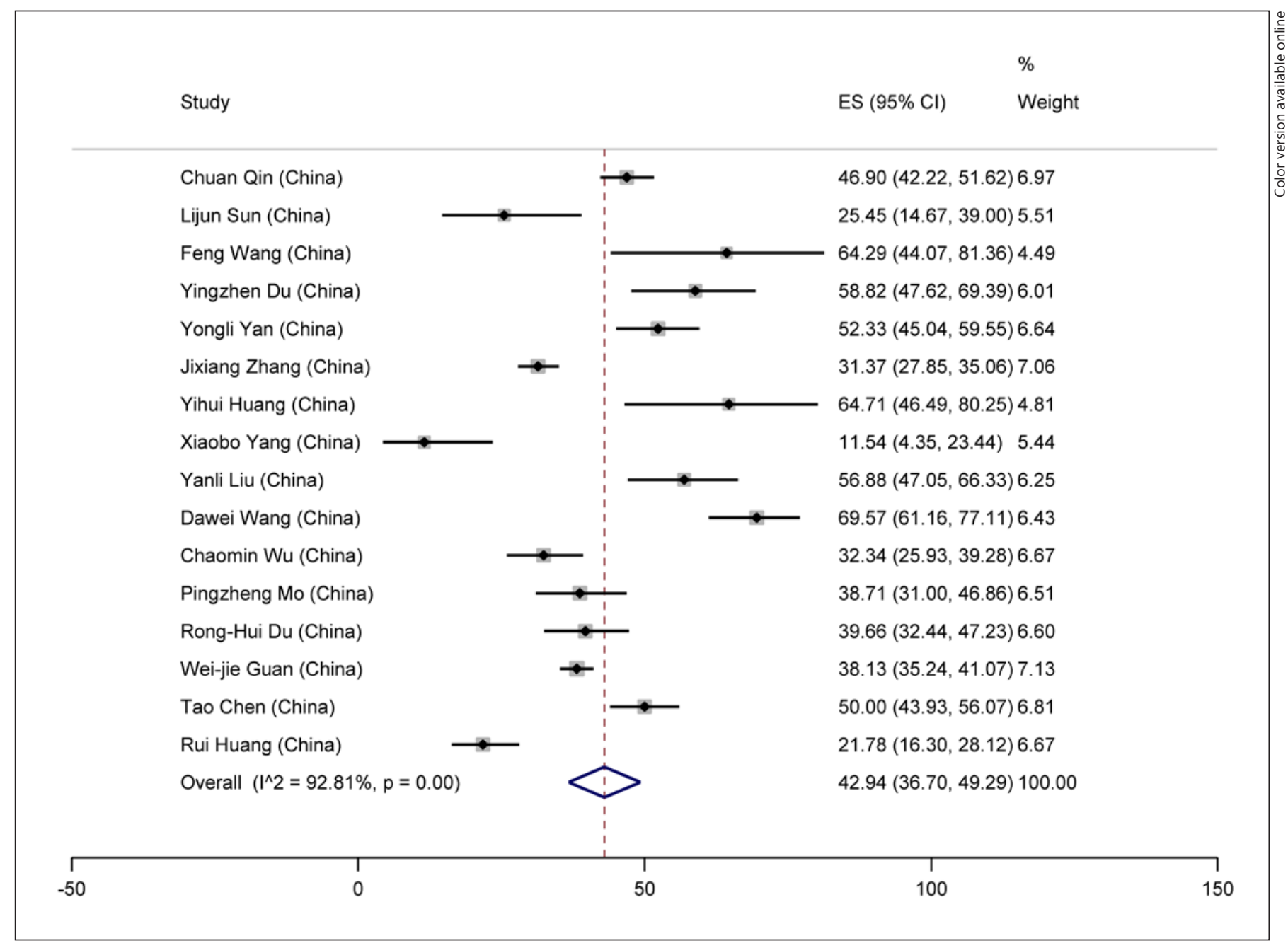

Fig. 5. Forest plot of the prevalence of fatigue in COVID-19 patients. Each square shows effect estimate of individual studies with their $95 \%$ CI. Size of squares is proportional to the weight of each study in the meta-analysis. In this plot, studies are shown in the order of publication date and first author's names (based on a random-effects model). COVID-19, coronavirus disease 2019.

hypogeusia/hyposmia, and impaired consciousness) and complications (such as [Meningo-]encephalopathy, cerebrovascular diseases, PNS disorders, and skeletal muscle injuries) $[12,33]$ are likely to occur in COVID-19 patients.

As mentioned before, coronaviruses are mostly known for upper respiratory tract infections; however, it has recently been observed that they can be correlated with inflammatory neurological diseases [34]. For this purpose, many animal studies have been conducted. Murray et al. [35] revealed that oligodendrocyte lysis and further demyelination in the CNS could occur during the acute phase in primate brains due to murine coronavirus repli- cation. Besides, Il-1 $\beta$, Il- 6 , and TNF- $\alpha$ levels increased in the spinal cord of infected subjects. Butler et al. [36] showed that intranasal infection with $\mathrm{HCoV}-\mathrm{OC} 43$ could lead to retrograde dissemination of the virus and infect the brainstem and pyriform cortex. According to these findings, the risk of neural involvement by SARS-CoV-2 should not be overlooked.

Various neurotropic mechanisms, such as ACE2 receptor expression in neural tissue, are designated for COVID-19. Following previous reports, ACE2 receptors are expressed in both glial cells and neurons. On the other hand, SARS-CoV-2 has around 20-fold higher receptor affinity than ACE2 receptors than SARS-CoV [37], indi- 


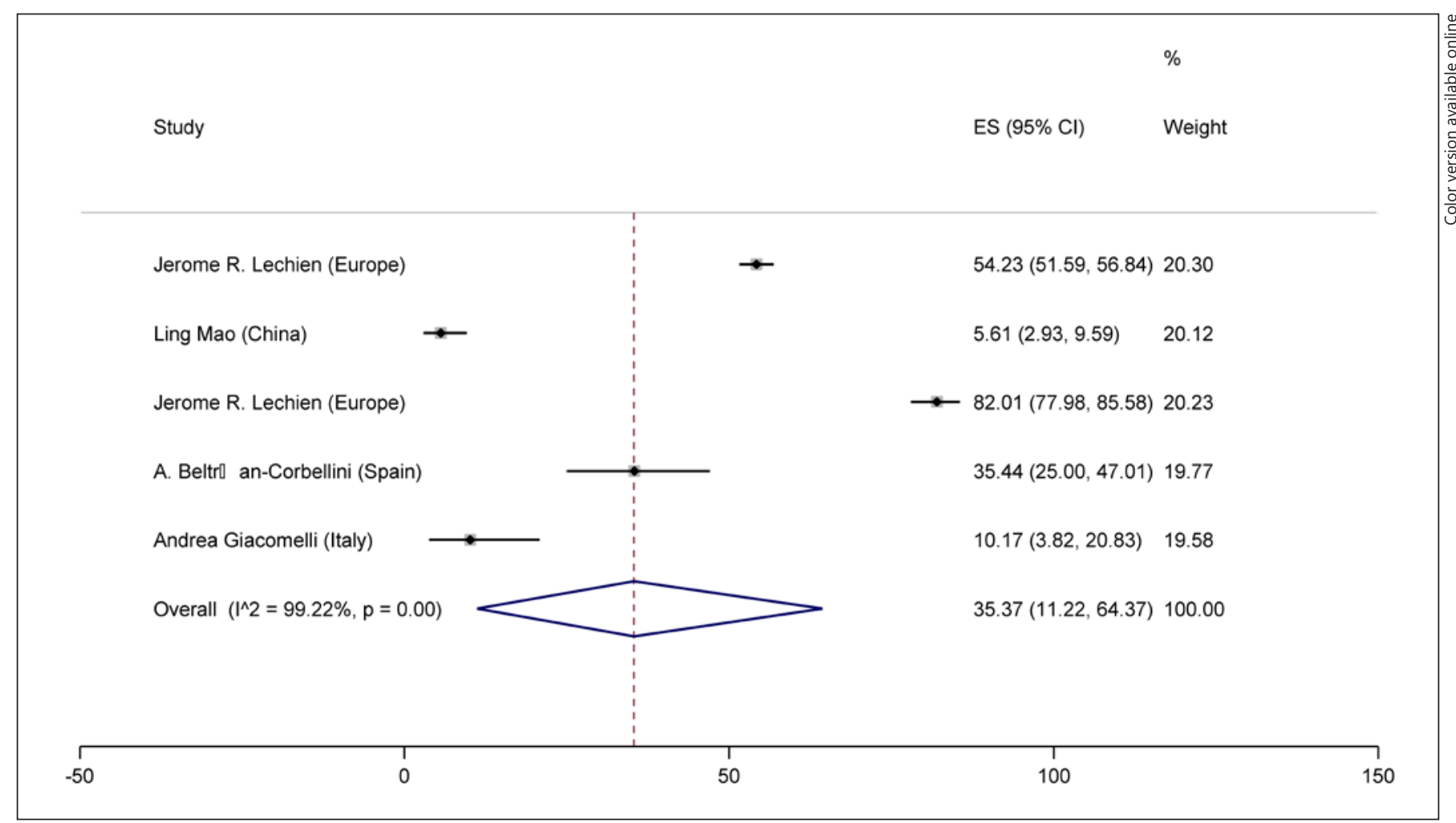

Fig. 6. Forest plot of the prevalence of gustatory dysfunction in COVID-19 patients. Each square shows effect estimate of individual studies with their $95 \%$ CI. Size of squares is proportional to the weight of each study in the meta-analysis. In this plot, studies are shown in the order of publication date and first author's names (based on a random-effects model). COVID-19, coronavirus disease 2019.

Table 2. Statistical analysis of reviewed studies

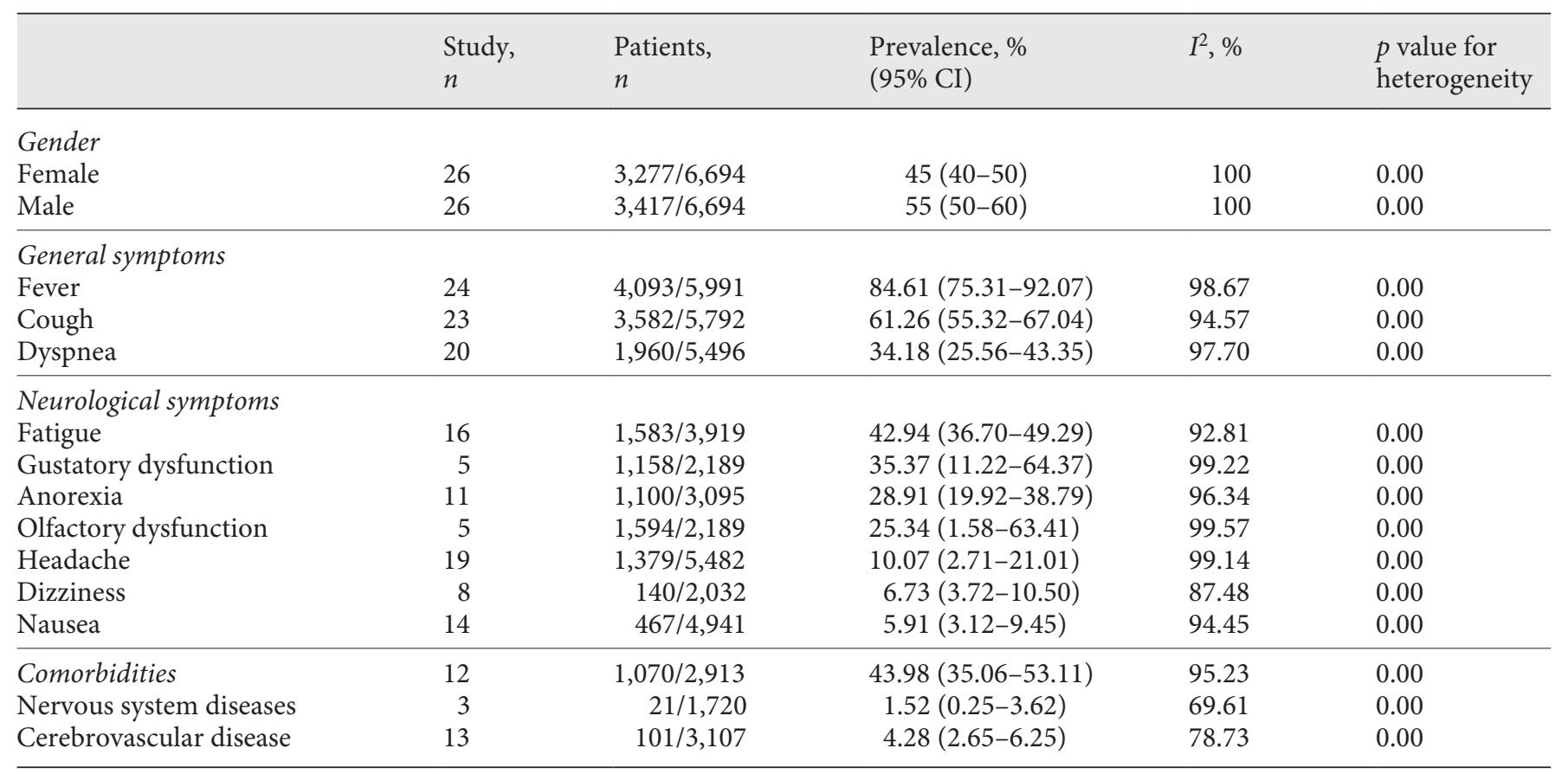




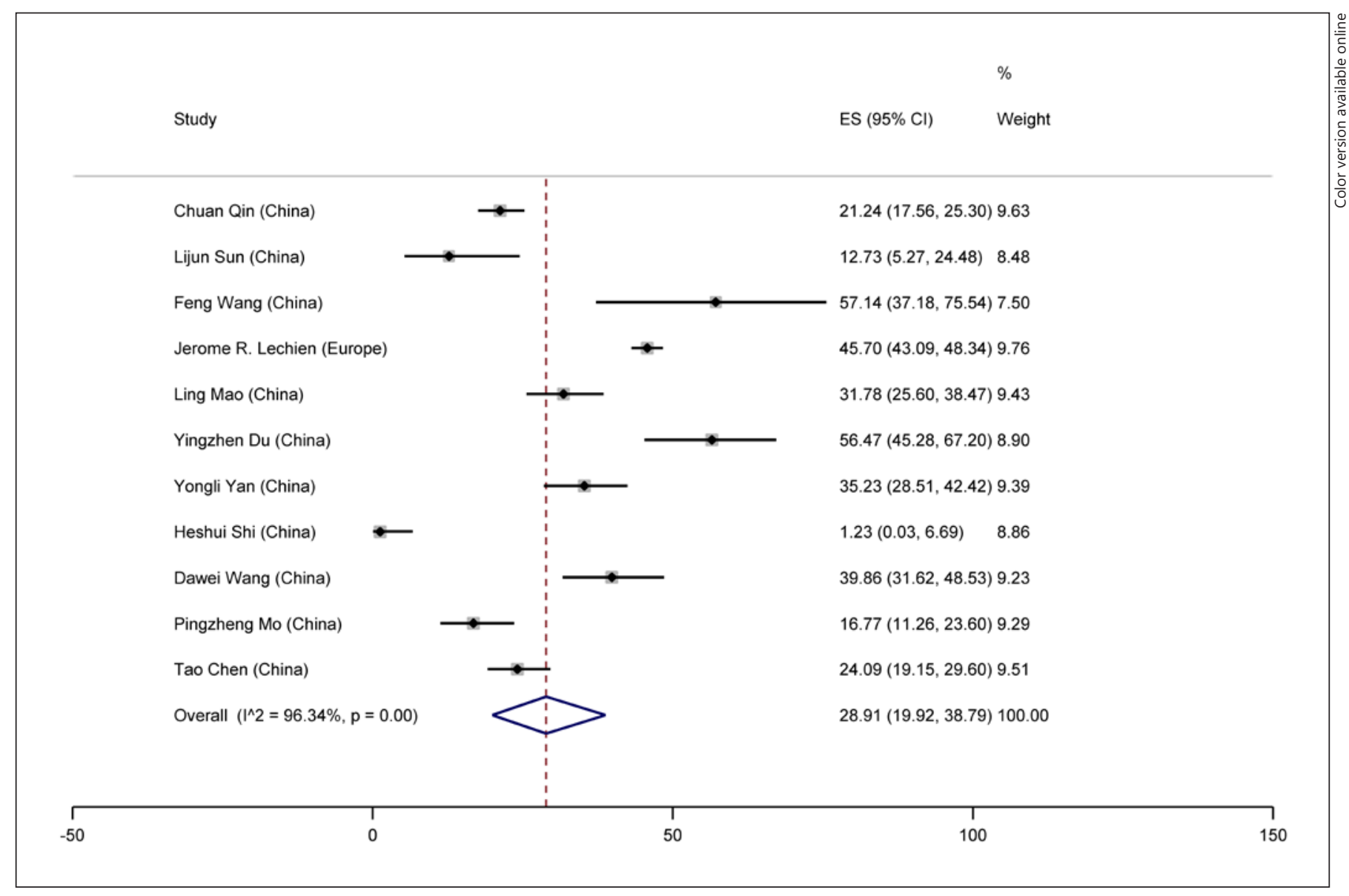

Fig. 7. Forest Plot of the prevalence of anorexia in COVID-19 patients. Each square shows effect estimate of individual studies with their $95 \%$ CI. Size of squares is proportional to the weight of each study in the meta-analysis. In this plot, studies are shown in the order of publication date and first author's names (based on a randomeffects model). COVID-19, coronavirus disease 2019.

cating a higher risk of neurologic infection in COVID-19 patients.

Mainly, SARS-COV-2 has 2 dissemination routes, through which it can infect the CNS: systemic circulation or ethmoid bone (i.e., olfactory nerve) [37]. When SARS$\mathrm{CoV}-2$ is present in general circulation, it can find its way through cerebral circulation, where slow blood flow through microcirculation can facilitate the interaction of its spike protein with ACE2 receptors on capillary endothelium. Subsequently, viral budding from the capillary endothelium and further endothelial disruption can support viral access to the brain [37]. This viral budding can also happen in neuronal tissues and cause neuronal damage without significant inflammation. It is also important to note that long before this neuronal damage occurs, the endothelial disruption in the capillaries of the brain can lead to bleeding within the cerebral tissue and cause critical consequences. Cribriform plate (near olfactory bulb) can be considered another entrance gate for SARS-CoV-2. Viral invasion through this pathway can be related to olfactory dysfunction observed among COVID-19 patients. As was evident, 25.3\% (95\% CI: 1.6$63.4 ; I^{2}=99.6 \%$ ) of patients represented different degrees of olfactory dysfunction from mild hyposmia to complete anosmia.

Gustatory dysfunction was also reported in 35.4\% (95\% CI: $11.2-64.4 ; I^{2}=99.2 \%$ ) of patients, which can be related to olfactory impairment or be directly related to the renin-angiotensin system (RAS). It has been revealed that RAS components (also ACE-2) are expressed in mouse taste organs [38]. In addition to the regulatory role of these components in the activity of taste organs, the presence of ACE-2 in these structures might explain gustatory dysfunction in COVID-19 patients [39]. 


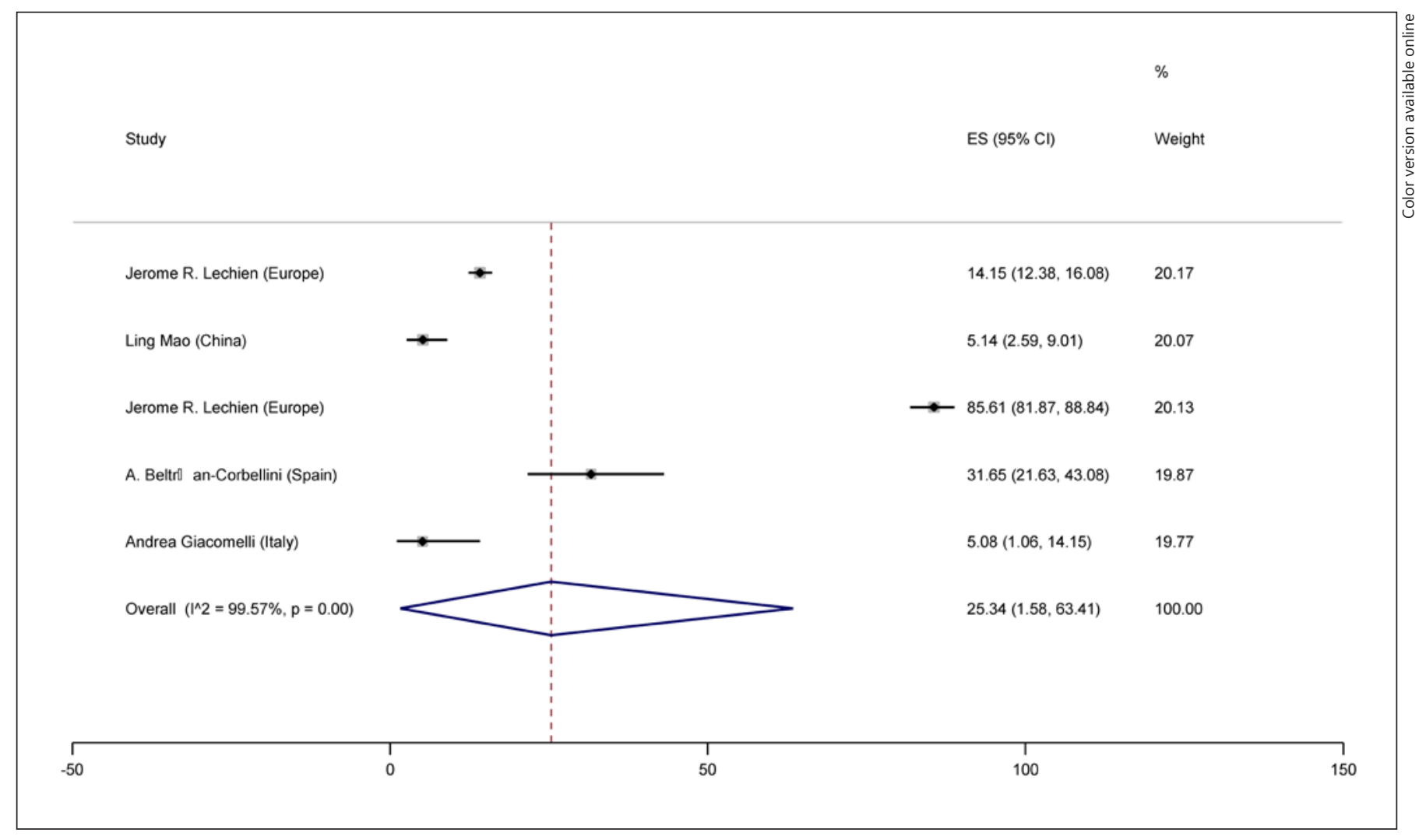

Fig. 8. Forest plot of the prevalence of olfactory dysfunction in COVID-19 patients. Each square shows effect estimate of individual studies with their $95 \%$ CI. Size of squares is proportional to the weight of each study in the meta-analysis. In this plot, studies are shown in the order of publication date and first author's names (based on a random-effects model). COVID-19, coronavirus disease 2019.

Anorexia was also another symptom observed in 28.9\% (95\% CI: $\left.19.9-38.8 ; I^{2}=96.3 \%\right)$ of patients. This loss of appetite can have different reasons. As Kinnaird et al. [40] reported that altered taste sensitivity could disturb taste processing in anorexia nervosa, appetite loss can have different reasons, such as gustatory dysfunction. Alternatively, it can be a result of the immune responses of the patient. The role of a dysfunctional immune system has been proved in both COVID-19 and anorexia nervosa (AN) [41]. For example, patients with AN have significantly increased TNF- $\alpha$, IL-1, IL-6, and TNF-receptor II levels, reducing the levels of C-reactive protein and IL-6 receptor. Increased levels of TNF-alpha and IL-6 have also been reported in COVID-19 [42]. Nevertheless, there is still more evidence needed to support this theory.

Moreover, headache was reported in 10.1\% (95\% CI: $\left.2.7-21.0 ; I^{2}=99.1 \%\right)$ of patients. According to initial reports, the intensity of headaches in the symptomatic COVID-19 patients was moderate to severe and new-onset (sudden to gradual). Their headache was bilateral with pulsating or pressing quality in the periorbital, forehead, or temporoparietal region [43]. The potential pathophysiological mechanisms that can lead to headache are direct activation of peripheral trigeminal nerve endings, increased pro-inflammatory cytokines in the cerebral circulation, vasculopathy, and hypoxia [43].

As one of the most common symptoms in many neurologic diseases [44], fatigue was reported in $42.9 \%$ (95\% CI: $36.7-49.3 ; I^{2}=92.8 \%$ ) of COVID-19 patients. Fatigue can be considered a general symptom in most diseases; however, it must be taken more seriously in COVID-19 patients due to certain potential risks of neurologic involvement. Like many other respiratory infections, COVID-19 can lead to a state of malaise and severe acute fatigue [45]. Moreover, chronic fatigue can happen with a prevalence of about $10 \%$ (within 3 months) due to COVID-19 [46]. Studies on post-viral fatigue have revealed that the development of chronic fatigue can be predicted by blood levels of IL- 6 and IL-10 in the acute phase of the disease [47]. These pro-inflammatory mediators (IL-6 


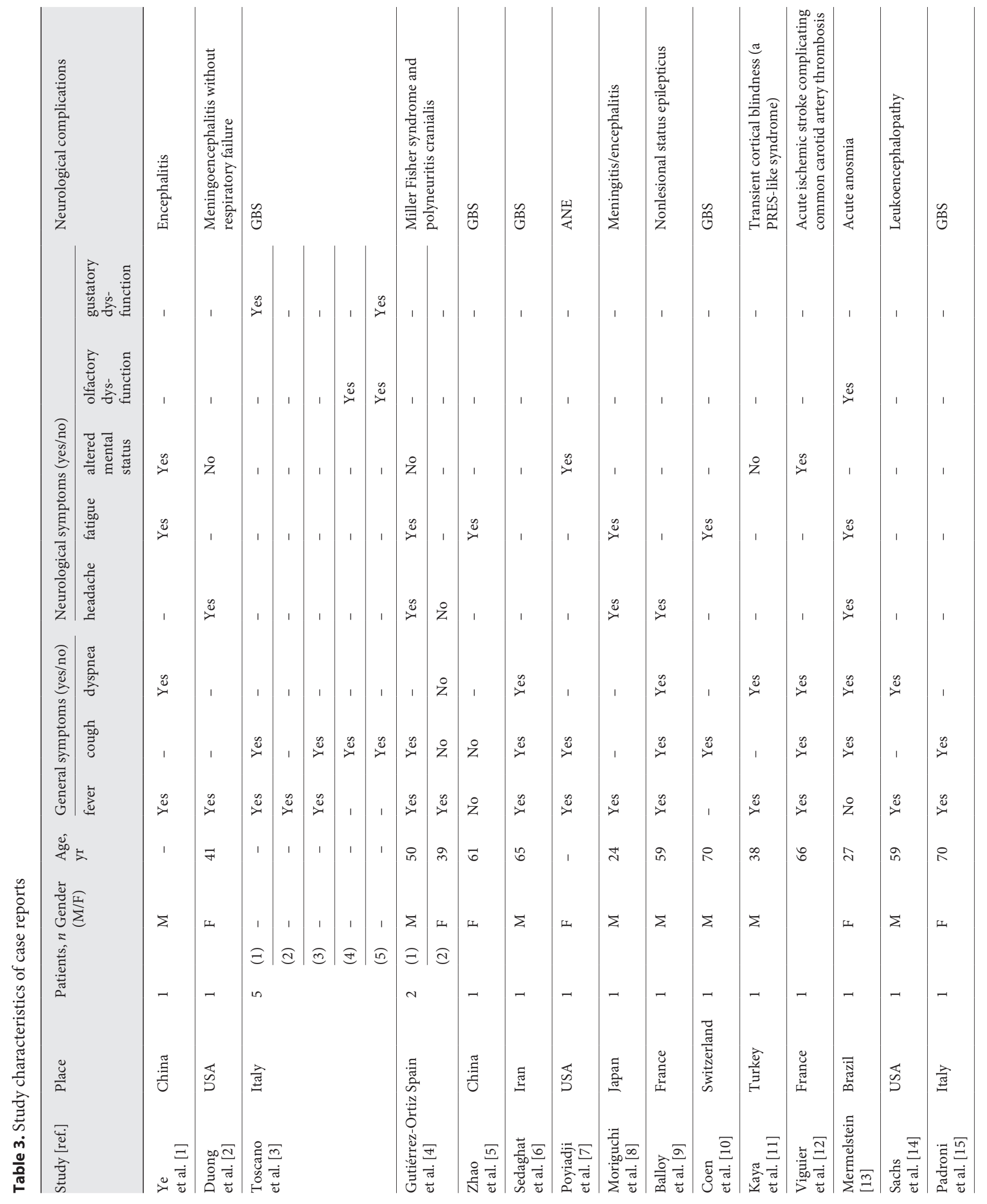




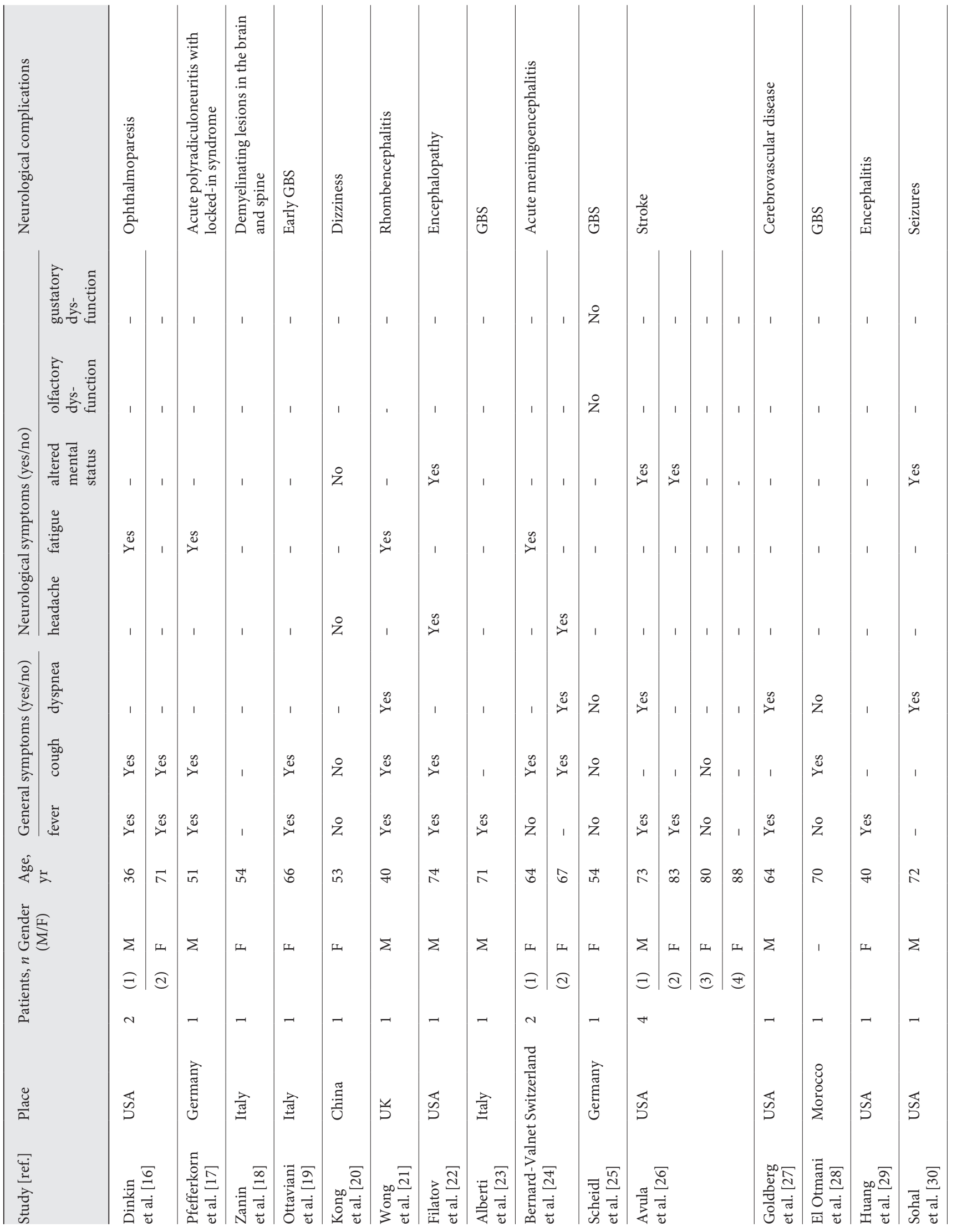




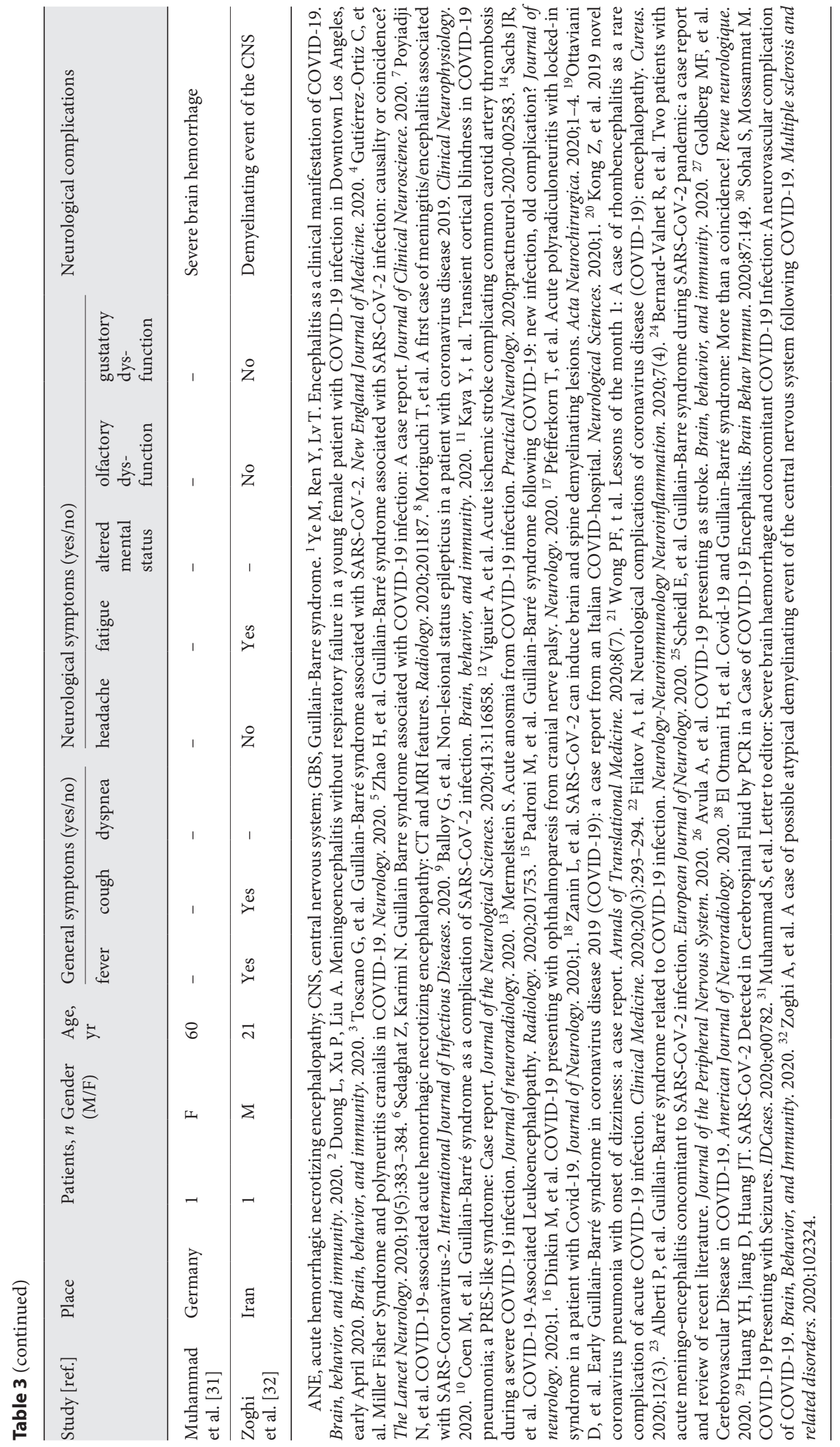




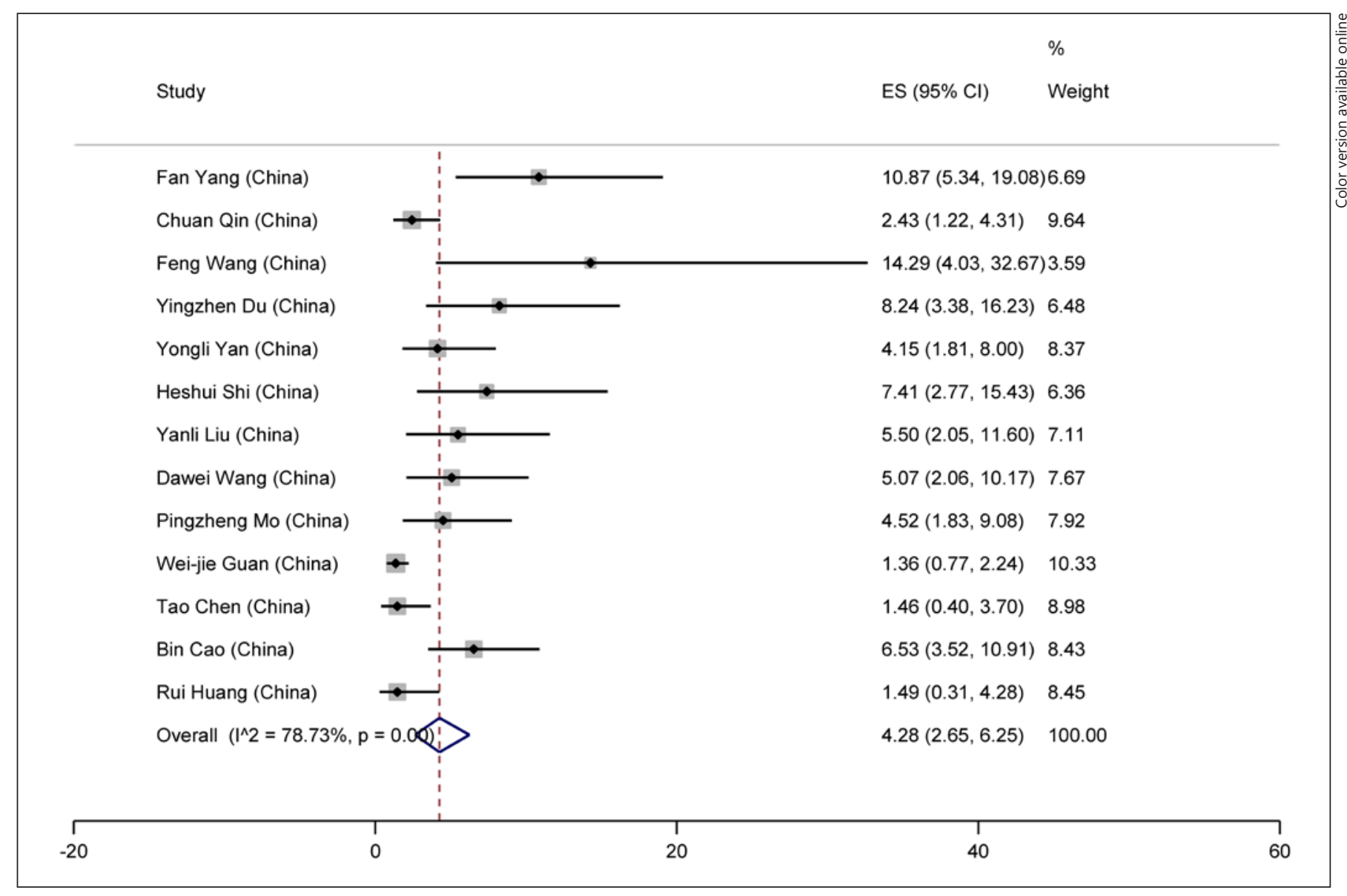

Fig. 9. Forest Plot of the prevalence of cerebrovascular disease in COVID-19 patients. Each square shows effect estimate of individual studies with their $95 \%$ CI. Size of squares is proportional to the weight of each study in the meta-analysis. In this plot, studies are shown in the order of publication date and first author's names (based on a random-effects model). COVID-19, coronavirus disease 2019.

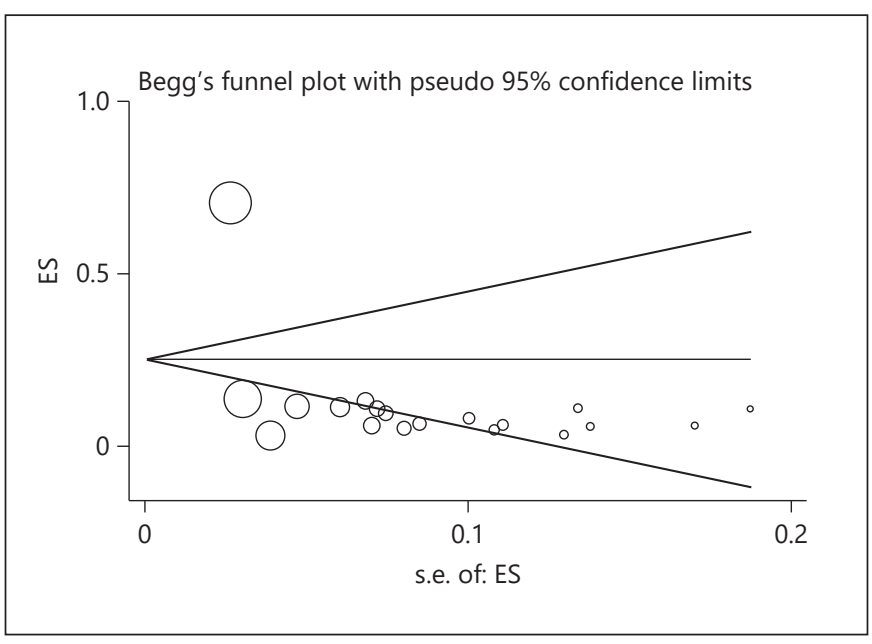

Fig. 10. Begg's funnel plot for publication bias. and IL-10) are present in the cytokine that occurs in severe cases of COVID-19 and suggests an immunologic pattern for this chronic fatigue [48]. Dizziness 6.7\% (95\% CI: $\left.3.7-10.5 ; I^{2}=87.5 \%\right)$ and nausea $5.9 \%$ (95\% CI: 3.19.5; $I^{2}=94.5 \%$ ) have also been reported in COVID-19 patients. These symptoms can also predict neurological involvement in COVID-19 patients, as they are common symptoms of encephalitis [49].

As the most prevalent neurological comorbidity in COVID-19, the cerebrovascular disease with $4.3 \%$ (95\% CI: $2.7-6.3 ; I^{2}=78.7 \%$ ) can put COVID-19 patients at significant risk. Cerebrovascular manifestations can also occur in patients as a result of COVID-19. This phenomenon can have different causes [24], including (1) ACE2 expression within venous and arterial tissues of the brain can make these structure susceptible for SARS-CoV-2 in- 
vasion [50], (2) cardiac arrhythmia as a result of COVID-19 can lead to cardio-embolism formation [13], (3) coagulation impairments as a result of COVID-19 can predispose to thromboembolic events [51], (4) preexisting cerebrovascular disorder can lead to intracranial stenosis (and hypo-perfused brain areas), which can increase the risk of ischemic stroke after COVID-19 severe infection [51].

Based on the case reports, the most critical COVIDrelated neurological complications were cerebrovascular diseases, encephalopathy, GBS, and seizure. As observed, the critical patients had more propensity to develop cerebrovascular diseases; their D-dimer levels were also higher than nonsevere patients. This can somehow justify the higher rate of cerebrovascular diseases in these patients [52]. In addition to this elevated level of d-dimer, intracranial cytokine storm has been found guilty in the pathophysiology of stroke/cerebrovascular disease [53]. Seizures were also reported in some cases. It has been hypothesized that this epileptic event can happen due to decreased seizure threshold caused by cytokine storm [54]. It seems unlikely that this virus can cause seizures directly. Patients with prolonged presence in ICU had a higher rate of encephalopathic complications than usually expected. Previous studies stated that this issue could be caused by prolonged administration of high doses of sedatives and anesthetics (to manage severe respiratory disease) [52]. It has also been reported that viremia and hypoxia can exacerbate these encephalopathic situations in COVID-19 patients [31]. GBS (alongside another inflammatory demyelinating polyneuropathy, like Miller Fisher syndrome) has also been reported in multiple cases of COVID-19. The pathophysiology of this phenomenon might be secondary to the neuroinvasive nature of SARS-CoV-2 and its ability to precipitate the demyelination process [55]. This peripheral demyelination can also be triggered by aberrant immune responses caused by viral infection-related inflammatory environments [56]. Finally, it should be noted that all of the scenarios described lately are hypotheses and require further studies to be confirmed.

\section{Conclusions}

The neuroinvasive propensity of SARS-CoV-2 has been reported in previous studies. This neuroinvasion can be associated with different neurologic symptoms, directly or indirectly. The most prevalent neurologic manifestations of COVID-19 are fatigue, gustatory dysfunc- tion, anorexia, olfactory dysfunction, headache, dizziness, and nausea. Cerebrovascular disorders can either be a risk factor for poorer prognosis in COVID-19 patients or occur as a critical complication in these patients. Although neurologic complications had not been reported in any observational study yet, GBS, encephalitis, and meningitis have been introduced as complications of COVID-19 in multiple case reports.

\section{Acknowledgement}

This study is related to the project No. 1399/34110 from Student Research Committee, Shahid Beheshti University of Medical Sciences, Tehran, Iran. We also appreciate the "Student Research Committee" and "Research \& Technology Chancellor" in Shahid Beheshti University of Medical Sciences for their financial support of this study.

\section{Statement of Ethics}

This study was conducted under the approval of Ethics Committee of Shahid Beheshti University of Medical Sciences (Ethics code: IR.SBMU.RETECH.REC.1399.082).

\section{Conflict of Interest Statement}

The authors have no conflicts of interest to declare.

\section{Funding Sources}

The authors did not receive any funding.

\section{Author Contributions}

K.V. and M.F. conceived of the presented idea, searched electronic databases, and collected the data. K.V. wrote the manuscript. F.S. performed the computation and analytical methods. M.H. and M.R supervised the findings of this work. A.T., M.S., M.H., and D.S. critically revised the manuscript. All authors discussed the results and contributed to the final manuscript.

\section{Availability of Data and Material}

All data analyzed or generated during this study are included in published articles available in Tables 1 and 3. 


\section{References}

1 WHO. Coronavirus disease (COVID-19) Situation Report-138. 2020 Jun. Available from: https://www.who.int/docs/defaultsource/coronaviruse/situation-reports/ 20200606 - covid-19-sitrep-138.pdf? sfvrsn=c8abfb17_4.

2 Sun P, Qie S, Liu Z, Ren J, Li K, Xi J. Clinical characteristics of hospitalized patients with SARS-CoV-2 infection: a single arm metaanalysis. J Med Virol. 2020;92(6):612-7.

3 Morfopoulou S, Brown JR, Davies EG, Anderson G, Virasami A, Qasim W, et al. Human coronavirus OC43 associated with fatal encephalitis. N Engl J Med. 2016;375(5):497-8.

4 Turgay C, Emine T, Ozlem K, Muhammet SP, Haydar AT. A rare cause of acute flaccid paralysis: human coronaviruses. J Pediatr Neurosci. 2015;10(3):280.

5 Al-Gethamy M, Corman VM, Hussain R, AlTawfiq JA, Drosten C, Memish ZA. A case of long-term excretion and subclinical infection with middle east respiratory syndrome coronavirus in a healthcare worker. Clin Infect Dis. 2015;60(6):973-4.

6 Duong L, Xu P, Liu A. Meningoencephalitis without respiratory failure in a young female patient with COVID-19 infection in Downtown Los Angeles, early April 2020. Brain Behav Immun. 2020;87:33.

7 Ye M, Ren Y, Lv T. Encephalitis as a clinical manifestation of COVID-19. Brain Behav Immun. 2020;88:945-6.

8 Moriguchi T, Harii N, Goto J, Harada D, Sugawara $\mathrm{H}$, Takamino J, et al. A first case of meningitis/encephalitis associated with SARS-coronavirus-2. Int J Infect Dis. 2020;94: 55-8.

9 Sedaghat Z, Karimi N. Guillain Barre syndrome associated with COVID-19 infection: a case report. J Clin Neurosci. 2020;76:233-5.

10 Zhao H, Shen D, Zhou H, Liu J, Chen S. Guillain-Barré syndrome associated with SARSCoV-2 infection: causality or coincidence? Lancet Neurol. 2020;19(5):383-4.

11 Gutiérrez-Ortiz C, Méndez-Guerrero A, Rodrigo-Rey S, Pedro-Murillo ES, BermejoGuerrero L, Gordo-Mañas R, et al. Miller Fisher syndrome and polyneuritis cranialis in COVID-19. Neurology. 2020;95(5):e601-5.

12 Mao L, Jin H, Wang M, Hu Y, Chen S, He Q, et al. Neurologic manifestations of hospitalized patients with coronavirus disease 2019 in Wuhan, China. JAMA Neurol. 2020;77(6): 683-90.

13 Wang D, Hu B, Hu C, Zhu F, Liu X, Zhang J, et al. Clinical characteristics of 138 hospitalized patients with 2019 novel coronavirus-infected pneumonia in Wuhan, China. JAMA. 2020;323(11):1061-9.

14 Giacomelli A, Pezzati L, Conti F, Bernacchia D, Siano M, Oreni L, et al. Self-reported olfactory and taste disorders in patients with severe acute respiratory coronavirus 2 infection: a cross-sectional study. Clin Infect Dis. 2020; 71(15):889-90.
15 Liu K, Pan M, Xiao Z, Xu X. Neurological manifestations of the coronavirus (SARSCoV-2) pandemic 2019-2020. J Neurol Neurosurg Psychiatry. 2020;91(6):669-70.

16 Das G, Mukherjee N, Ghosh S. Neurological insights of COVID-19 pandemic. ACS Chem Neurosci. 2020;11(9):1206.

17 Li YC, Bai WZ, Hashikawa T. The neuroinvasive potential of SARS-CoV-2 may play a role in the respiratory failure of COVID-19 patients. J Med Virol. 2020;92(6):552-5.

18 Yashavantha Rao H, Jayabaskaran C. The emergence of a novel coronavirus (SARS$\mathrm{CoV}-2$ ) disease and their neuroinvasive propensity may affect in COVID-19 patients. Med Virol. 2020;92(7):786-90

19 Li Z, Liu T, Yang N, Han D, Mi X, Li Y, et al. Neurological manifestations of patients with COVID-19: potential routes of SARS-CoV-2 neuroinvasion from the periphery to the brain. Front Med. 2020;14:533-41.

20 Torabi A, Mohammadbagheri E, Dilmaghani NA, Bayat A-H, Fathi M, Vakili K, et al. Proinflammatory cytokines in the olfactory mucosa result in COVID-19 induced anosmia. ACS Chem Neurosci. 2020;11(13):1909-13.

21 Netland J, Meyerholz DK, Moore S, Cassell M, Perlman S. Severe acute respiratory syndrome coronavirus infection causes neuronal death in the absence of encephalitis in mice transgenic for human ACE2. J Virol. 2008; 82(15):7264-75.

22 Cashion MF, Banks WA, Bost KL, Kastin AJ. Transmission routes of HIV-1 gp120 from brain to lymphoid tissues. Brain Res. 1999; 822(1-2):26-33.

23 Bostanciklioğlu M. SARS-CoV2 entry and spread in the lymphatic drainage system of the brain. Brain Behav Immun. 2020;87:1223.

24 Larson AS, Savastano L, Kadirvel R, Kallmes DF, Hassan AE, Brinjikji W. COVID-19 and the cerebrovascular-cardiovascular systems: what do we know so far? J Am Heart Assoc. 2020;9:e016793.

25 Freeman MF, Tukey JW. Transformations related to the angular and the square root. Ann Math Statist. 1950;21(4):607-11.

26 Wells G. The newcastle-ottawa scale (NOS) for assessing the quality of nonrandomised studies in meta-analysis. Available from: http: //www.ohri.ca/programs/clinical_epidemiology.oxford.htm.2004.

27 Liberati A, Altman DG, Tetzlaff J, Mulrow C, Gøtzsche PC, Ioannidis JPA, et al. The PRISMA statement for reporting systematic reviews and meta-analyses of studies that evaluate health care interventions: explanation and elaboration. PLoS Med. 2009; 6(10): e1000100-e34.

28 Ghebreyesus TA. WHO director-general's opening remarks at the media briefing on COVID-19-11 March 2020. Geneva, Switzerland: World Health Organization; 2020. Available from: https://www.who.int/dg/ speeches/detail/who-director-general-sopening-remarks-atthe-media-briefing-oncovid-19-11-march-2020.

29 Niazkar M, Niazkar HR. COVID-19 outbreak: application of multi-gene genetic programming to country-based prediction models. Electron J Gen Med. 2020;17(5):em247.

30 Lauer SA, Grantz KH, Bi Q, Jones FK, Zheng $\mathrm{Q}$, Meredith HR, et al. The incubation period of coronavirus disease 2019 (COVID-19) from publicly reported confirmed cases: estimation and application. Ann Intern Med. 2020;172(9):577-82.

31 Wu Y, Xu X, Chen Z, Duan J, Hashimoto K, Yang L, et al. Nervous system involvement after infection with COVID-19 and other coronaviruses. Brain Behav Immun. 2020;87:1822.

32 Grant MC, Geoghegan L, Arbyn M, Mohammed Z, McGuinness L, Clarke EL, et al., The prevalence of symptoms in 24,410 adults infected by the novel coronavirus (SARSCoV-2; COVID-19): a systematic review and meta-analysis of 148 studies from 9 countries. PLoS One. 2020 Jun 23;15(6):e0234765

33 Helms J, Kremer S, Merdji H, Clere-Jehl R, Schenck M, Kummerlen C, et al. Neurologic features in severe SARS-CoV-2 infection. N Engl J Med. 2020;382(23):2268-70.

34 De Santis G. SARS-CoV-2: a new virus but a familiar inflammation brain pattern. Brain Behav Immun. 2020;87:95-6.

35 Murray RS, Cai GY, Hoel K, Zhang JY, Soike KF, Cabirac GF. Coronavirus infects and causes demyelination in primate central nervous system. Virology. 1992;188(1):274-84.

36 Butler N, Pewe L, Trandem K, Perlman S. Murine encephalitis caused by $\mathrm{HCoV}-\mathrm{OC} 43$, a human coronavirus with broad species specificity, is partly immune-mediated. Virology. 2006;347(2):410-21.

37 Baig AM, Khaleeq A, Ali U, Syeda H. Evidence of the COVID-19 virus targeting the CNS: tissue distribution, host-virus interaction, and proposed neurotropic mechanisms. ACS Chem Neurosci. 2020;11(7):995-8.

38 Shigemura N, Takai S, Hirose F, Yoshida R, Sanematsu K, Ninomiya Y. Expression of renin-angiotensin system components in the taste organ of mice. Nutrients. 2019;11(9): 2251.

39 Bigiani A. Gustatory dysfunctions in COVID-19 patients: possible involvement of taste renin-angiotensin system (RAS). Eur Arch Otorhinolaryngol. 2020;277:2395.

40 Kinnaird E, Stewart C, Tchanturia K. Taste sensitivity in anorexia nervosa: a systematic review. Int J Eat Disord. 2018;51(8):771-84.

41 DeSarbo JR, DeSarbo L. Anorexia nervosa and COVID-19. Curr Psychiatry. 2020;19(8): 23-8.

42 Qin C, Zhou L, Hu Z, Zhang S, Yang S, Tao Y, et al. Dysregulation of immune response in patients with COVID-19 in Wuhan, China. Clin Infect Dis. 2020;71(15):762-68. 
43 Bolay H, Gül A, Baykan B, COVID-19 is a real headache! Headache J Head Face Pain;60(7): 1415-21.

44 Kluger BM, Krupp LB, Enoka RM. Fatigue and fatigability in neurologic illnesses: proposal for a unified taxonomy. Neurology. 2013;80(4):409-16.

45 Borges do Nascimento IJ, Cacic N, Abdulazeem HM, von Groote TC, Jayarajah U, Weerasekara I, et al. Novel coronavirus infection (COVID-19) in humans: a scoping review and meta-analysis. J Clin Med. 2020; 9(4):941.

46 Williams FMK, Muirhead N, Pariante C. Covid-19 and chronic fatigue. BMJ. 2020;370: $\mathrm{m} 2922$.

47 Russell A, Hepgul N, Nikkheslat N, Borsini A, Zajkowska Z, Moll N, et al. Persistent fatigue induced by interferon-alpha: a novel, inflammation-based, proxy model of chronic fatigue syndrome. Psychoneuroendocrinology. 2019; 100:276-85.

48 Vaninov N. In the eye of the COVID-19 cytokine storm. Nat Rev Immunol. 2020;20(5): 277.

49 Koskiniemi M, Donner M, Pettay O. Clinical appearance and outcome in mumps encephalitis in children. Acta Paediatr Scand. 1983; 72(4):603-9.

50 Hamming I, Timens W, Bulthuis MLC, Lely AT, Navis GJ, van Goor H. Tissue distribution of ACE2 protein, the functional receptor for SARS coronavirus. A first step in understanding SARS pathogenesis. J Pathol. 2004;203(2): 631-7.

51 Li Y, Li M, Wang M, Zhou Y, Chang J, Xian $\mathrm{Y}$, et al. Acute cerebrovascular disease following COVID-19: a single center, retrospective, observational study. Stroke Vasc Neurol. 2020;5(3):279-84.
52 Jasti M, Nalleballe K, Dandu V, Onteddu S. A review of pathophysiology and neuropsychiatric manifestations of COVID-19. J Neurol. 2020;1.

53 Oxley TJ, Mocco J, Majidi S, Kellner CP, Shoirah H, Singh IP, et al. Large-vessel stroke as a presenting feature of Covid-19 in the young. N Engl J Med. 2020;382(20):e60.

54 Libbey JE, Kennett NJ, Wilcox KS, White HS, Fujinami RS. Interleukin-6, produced by resident cells of the central nervous system and infiltrating cells, contributes to the development of seizures following viral infection. J Virol. 2011;85(14):6913-22.

55 Hosking MP, Lane TE. The role of chemokines during viral infection of the CNS. PLoS Pathog. 2010;6(7):e1000937.

56 Fairweather D, Frisancho-Kiss S, Rose NR. Viruses as adjuvants for autoimmunity: evidence from Coxsackievirus-induced myocarditis. Rev Med Virol. 2005;15(1):17-27. 